\title{
Natural history and surgical treatment of chordoma: a retrospective cohort study
}

\author{
História natural e tratamento cirúrgico de cordoma: um estudo retrospectivo \\ de coorte
}

\author{
Samuel Aguiar Júnior', Wesley Pereira Andrade", Glauco Baiocchi', Gustavo Cardoso Guimarães', Isabela Werneck Cunha"', \\ Daniel Alvarez Estradalv, Sergio Hideki Suzuki"v, Luiz Paulo Kowalskiv , Ademar Lopes ${ }^{\mathrm{vI}}$
}

Hospital A. C. Camargo, São Paulo, Brazil

'MD, PhD. Surgical Oncologist, Department of Pelvic Surgery, Hospital A. C. Camargo, São Paulo, Brazil.

"MD, MSc. Surgical Oncologist, Department of Pelvic Surgery, Hospital A. C. Camargo, São Paulo, Brazil.

"'MD, PhD. Pathologist, Department of Pathology, Hospital A. C. Camargo, São Paulo, Brazil.

"MD. Neurosurgeon, Department of Neurosurgery, Hospital A. C. Camargo, São Paulo, Brazil. 'MD, PhD. Head and Neck Surgeon, Department of Head and Neck Surgery, São Paulo, Brazil.

"MD, PhD. Head of Department of Pelvic Surgery, Hospital A. C. Camargo, São Paulo, Brazil.

\section{KEY WORDS:}

Chordoma.

Surgical procedures, operative.

Recurrence.

Survival.

Risk factors.

Mortality.

\section{PALAVRAS-CHAVE:}

Cordoma.

Procedimentos cirúrgicos operatórios.

Recidiva.

Sobrevivência.

Fatores de risco.

Mortalidade.

\section{ABSTRACT}

CONTEXT AND OBJECTIVE: Chordoma is a rare tumor with a high risk of locoregional recurrences. The aim of this study was analyze the long-term results from treating this pathological condition. DESIGN AND SETTING: Cohort study in a single hospital in São Paulo, Brazil.

METHODS: This was a retrospective cohort study on 42 patients with chordoma who were treated at Hospital A. C. Camargo between 1980 and 2006. The hospital records were reviewed and a descriptive analysis was performed on the clinical-pathological variables. Survival curves were estimated using the Kaplan-Meier method and these were compared using the log-rank test.

RESULTS: Nineteen patients were men and 23 were women. Twenty-five tumors (59.5\%) were located in the sacrum, eleven (26.2\%) in the skull base and six (14.3\%) in the mobile spine. Surgery was performed on 28 patients (66.7\%). The resection was considered to have negative margins in 14 cases and positive margins in 14 cases. The five-year overall survival (OS) was $45.4 \%$. For surgical patients, the five-year OS was $64.3 \%$ (82.2\% for negative margins and $51.9 \%$ for positive margins). In the inoperable group, OS was $37.7 \%$ at 24 months and $0 \%$ at five years.

CONCLUSION: Complete resection is related to local control and definitively has a positive impact on long-term survival.

\section{RESUMO}

CONTEXTO E OBJETIVO: Cordoma é um tumor raro e com alto risco de recidiva locorregional. O objetivo deste estudo foi analisar os resultados a longo prazo do tratamento dessa doença.

TIPO DE ESTUDO E LOCAL: Estudo de coorte realizado em um único hospital em São Paulo, Brasil. MÉTODOS: Estudo de coorte retrospectivo com 42 pacientes com cordoma tratados de 1980 e 2006 no Hospital A. C. Camargo. Os prontuários foram revistos e foi realizada a análise descritiva das variáveis clínicas e patológicas. As curvas de sobrevida foram estimadas pelo método de Kaplan-Meier e a comparação entre elas, pelo teste de log-rank.

RESULTADOS: Dezenove pacientes eram homens e 23, mulheres. Vinte e cinco tumores (59,5\%) estavam localizados no sacro, 11 (26,2\%) na base do crânio e 6 (14,3\%), na coluna móvel. A cirurgia foi realizada em 28 pacientes $(66,7 \%)$. A ressecção foi considerada como tendo margens negativas em 14 casos e margens comprometidas em 14 pacientes. A sobrevida global (SG) em 5 anos foi de 45,4\%. Para os pacientes cirúrgicos, a SG em 5 anos foi de $64,3 \%$ (82,2\% para as margens negativas e $51,9 \%$ de margens positivas). No grupo inoperável, a SG em 24 meses foi de 37,7\% e 0\% em 5 anos.

CONCLUSÃO: A ressecção completa está relacionada com o controle local e, definitivamente, tem impacto positivo na sobrevida a longo prazo. 


\section{INTRODUCTION}

Chordoma is a rare malignant neoplasm that arises from primitive notochord remnants. It occurs exclusively in the axial skeleton and has a predilection for the sacrum (50\%), base of the skull (35\%) and mobile spine (15\%). ${ }^{1-3}$ Although considered to be a low-grade and slow-growing tumor, a poor long-term prognosis is generally observed due to extensive local recurrences and secondary complications. Metastasis is usually reported as a late event. ${ }^{4}$

Proximity to neurological and other vital structures is the major challenge in making therapeutic decisions. Surgery is the mainstay of treatment and local control is better achieved with en bloc resection of the tumor with safe margins. ${ }^{1,2,4,5}$ Because of the poor responsiveness to radiotherapy, this treatment option is generally used only as adjuvant treatment after incomplete surgical resection, or in palliative management. ${ }^{1}$ Chemotherapy usually results in low response rates. Only a few clinical series have reported the use of chemotherapy for managing chordoma, which is generally used in the latter course of the disease and only as palliative treatment. ${ }^{6,7}$

Because of the rarity of this disease, only a few retrospective series have been published.

\section{OBJECTIVE}

The purpose of this study was to describe a single institution's experience of treating chordoma.

\section{METHODS}

This was a retrospective cohort study on all 42 consecutive patients with chordoma who were treated in the A. C. Camargo Cancer Center between 1980 and 2006. The hospital records were reviewed and a descriptive analysis was performed on the clinical-pathological variables. Survival curves were estimated using the KaplanMeier method and these were compared using the log-rank test.

The patients were evaluated retrospectively in relation to age, sex, duration of symptoms until diagnosis, chordoma location, symptomatology, biopsy or surgery performed before being admitted into our hospital, treatment and surgical margins, adjuvant treatment, local recurrence, systemic metastasis, complications arising from disease evolution or treatment and mortality. Patients were considered to be asymptomatic if their tumors were discovered accidentally through image examinations conducted for another reason. The surgical resections were considered to have negative margins if they had negative macroscopic or microscopic margins; and positive margins if they had positive macroscopic margins.

\section{Statistical analysis}

The database was set up in the Statistical Package for the Social Sciences, version 16.0 for Mac (SPSS, Inc., Chicago, IL, USA).
The length of follow-up was considered to be from the date of the patient's admission to the date of the last objective follow-up information. The survival curves were estimated by means of the Kaplan-Meier method and the curves were compared using the log-rank test. In all the tests, $\mathrm{P}<0.05$ was taken to be statistically significant.

\section{RESULTS}

Nineteen patients were male (45.2\%) and 23 were female (54.8\%). At the time of diagnosis, the median age was 47 years (range: 5-86). The median follow-up was 28.5 months and the mean was 49.3 months (range: 1-261.6). The patients' distribution according to their main characteristics is shown in Table 1. Data on the period of time from symptom onset to diagnosis were available for 37 patients (88\%) with a median of 19 months (range: 1-48).

Twenty-five tumors (59.5\%) were located in the sacrum, eleven $(26.2 \%)$ in the skull base and six (14.3\%) in the mobile spine (three cervical, two thoracic and one lumbar). In relation to the eleven tumors of the clivus (skull base), the main symptoms were pain (six cases), diplopia or strabismus (six cases), paresthesia (two cases), dysarthria (one case) and alteration of the motor function of the tongue (one case).

Regarding the 25 sacrococcygeal tumors, the main symptoms were pain (19 cases), presence of tumor mass in the sacrococcygeal region perceived by the patient (six cases), motor deficit or sensory neuropathy in lower limbs (six cases), constipation/bowel dysfunction (three cases) and bladder dysfunction (one case).

Twenty-eight patients (66.7\%) were considered to be in the surgical treatment group and 14 patients (33.3\%) were considered to be in the nonsurgical treatment group.

\section{Surgical treatment}

Nineteen patients (45.2\%) had undergone previous surgical procedures in other institutions before admission. Only one (5.3\%) had undergone complete resection previously, while 18 (94.7\%) had had incomplete resections. Among the 18 patients who had previously undergone incomplete resections, 12 (66.7\%) underwent salvage surgical procedures in our hospital. Five had negative margins and seven had resections with positive margins. The other six patients $(33.3 \%)$ were considered to present operable disease, based on image analysis. Since these patients showed persistent disease that was measurable on images, they were considered to be in the nonsurgical group.

Twenty-eight patients $(66.7 \%)$ were included in the surgical group of treatment. The surgical resection was considered to present negative margins in 14 cases (50\%) and positive margins in the other 14 cases (50\%).

The tumor site influenced the extent of the resection, since neurological structures are more involved when tumors are 
Table 1. Treatment data and clinical outcomes among 42 chordoma patients

\begin{tabular}{|c|c|c|c|c|c|c|c|c|c|c|}
\hline no & Age & Gender & Location & Margins & Adj. treatment & Recurrence & Progression & Metastasis & Death & Status \\
\hline 1 & 26 & Female & Clivus & Neg & RT & No & - & No & No & NED \\
\hline 2 & 5 & Male & Clivus & Neg & - & Yes & - & No & No & AWD \\
\hline 3 & 6 & Female & Clivus & Neg & - & No & - & No & No & NED \\
\hline 4 & 26 & Female & Clivus & Pos & - & - & Yes & No & No & DOD \\
\hline 5 & 32 & Male & Clivus & Pos & - & - & Yes & No & Yes & DOD \\
\hline 6 & 37 & Female & Clivus & Pos & - & - & No & No & No & AWD \\
\hline 7 & 39 & Female & Clivus & Pos & RT & - & No & No & No & NED \\
\hline 8 & 50 & Female & Clivus & Pos & RT & - & Yes & No & Yes & DOD \\
\hline 9 & 10 & Female & Clivus & - & RT & - & Yes & No & Yes & DOD \\
\hline 10 & 18 & Female & Clivus & - & CT & - & Yes & No & Yes & DOD \\
\hline 11 & 22 & Female & Clivus & - & RT & - & Yes & No & Yes & DOD \\
\hline 12 & 11 & Male & Cervical spine & Neg & - & No & - & No & No & NED \\
\hline 13 & 21 & Female & Cervical spine & Pos & - & - & No & No & No & NED \\
\hline 14 & 52 & Male & Cervical spine & Pos & RT & - & Yes & No & Yes & DOD \\
\hline 15 & 59 & Female & Lumbar spine & - & CT & - & Yes & Skin & Yes & DOD \\
\hline 16 & 19 & Male & Thoracic spine & Pos & - & - & Yes & No & Yes & DOD \\
\hline 17 & 28 & Female & Thoracic spine & - & Palliative & - & Yes & No & No & AWD \\
\hline 18 & 56 & Female & Sacrococcygeal & Neg & RT & Yes* & - & No & No & AWD \\
\hline 19 & 57 & Male & Sacrococcygeal & Neg & - & No & - & No & No & NED \\
\hline 20 & 58 & Male & Sacrococcygeal & Neg & - & Yes & - & No & Yes & DOD \\
\hline 21 & 59 & Male & Sacrococcygeal & Neg & - & No & - & No & No & NED \\
\hline 22 & 63 & Female & Sacrococcygeal & Neg & - & Yes & - & No & Yes & DOD \\
\hline 23 & 64 & Female & Sacrococcygeal & Neg & - & No & - & No & No & NED \\
\hline 24 & 66 & Female & Sacrococcygeal & Neg & RT & No & - & No & No & NED \\
\hline 25 & 68 & Male & Sacrococcygeal & Neg & - & Yes & - & No & Yes & NED \\
\hline 26 & 75 & Male & Sacrococcygeal & Neg & RT & Yes $^{*}$ & - & No & No & NED \\
\hline 27 & 76 & Female & Sacrococcygeal & Neg & - & No & - & No & No & NED \\
\hline 28 & 28 & Male & Sacrococcygeal & Pos & - & - & Yes & Lung and liver & No & AWD \\
\hline 29 & 37 & Male & Sacrococcygeal & Pos & - & - & No & Lung and liver & No & AWD \\
\hline 30 & 46 & Female & Sacrococcygeal & Pos & - & - & Yes & No & Yes & DOD \\
\hline 31 & 48 & Male & Sacrococcygeal & Pos & - & - & Yes & Lung and liver & Yes & DOD \\
\hline 32 & 50 & Female & Sacrococcygeal & Pos & RT & - & Yes & No & Yes & DOD \\
\hline 33 & 69 & Male & Sacrococcygeal & Pos & RT & - & No & No & Yes & DOD \\
\hline 34 & 6 & Female & Sacrococcygeal & - & Palliative & - & No & No & Yes & DOD \\
\hline 35 & 18 & Female & Sacrococcygeal & - & RT & - & No & No & No & AWD \\
\hline 36 & 39 & Male & Sacrococcygeal & - & RT & - & No & Bone & Yes & DOD \\
\hline 37 & 42 & Male & Sacrococcygeal & - & RT & - & No & No & Yes & DOD \\
\hline 38 & 48 & Female & Sacrococcygeal & - & RT & - & No & No & No & AWD \\
\hline 39 & 54 & Male & Sacrococcygeal & - & RT & - & No & No & - & - \\
\hline 40 & 65 & Male & Sacrococcygeal & - & RT & - & Yes & No & Yes & DOD \\
\hline 41 & 68 & Male & Sacrococcygeal & - & RT & - & No & Lung & Yes & DOD \\
\hline 42 & 86 & Female & Sacrococcygeal & - & RT & - & No & No & Yes & DOD \\
\hline
\end{tabular}

$\mathrm{M}=$ male; $\mathrm{F}=$ female; $\mathrm{POS}=$ positive margins; $\mathrm{NEG}=$ negative margins; $\mathrm{CT}=$ chemotherapy; $\mathrm{RT}=$ radiation therapy; $\mathrm{Adj}$. = adjuvant; $\mathrm{DOD}=$ died of disease; $\mathrm{NED}=$ no evidence of disease; $\mathrm{DOC}=$ died of other causes; $\mathrm{AWD}=$ alive with disease. ${ }^{*}$ Recurrence with new resection with positive margins.

located in the clivus or mobile spine, rather than in the sacral location. Regarding the resection of the 16 sacral tumors, ten $(62.5 \%)$ were considered to have negative margins and six (37.5\%) were considered to have positive margins. Among the eight skull base tumor resections, three (37.5\%) were considered to have negative margins and five $(62.5 \%)$ were considered to have positive margins. Out of the six patients with mobile spine tumors, only four underwent surgical treatment. Just one (25\%) had negative margins (cervical spine tumor) and the other three (75\%) had positive margins (two cervical and one thoracic spine tumors). When we grouped the patients with mobile spine and clivus tumors, we found that the sacral tumors had higher rates 
of negative margins (62.5\% versus 33.3\%), although this did not reach statistical significance $(\mathrm{P}=0.25)$.

Adjuvant treatment was performed with radiotherapy in nine cases $(32.1 \%$ ), of which four had negative margins (one skull base and three sacral tumors) and five had positive margins (two skull base, one mobile spine and two sacral tumors).

Neurological deficit was the most notable surgical morbidity. Out of the sixteen patients who underwent sacral resections, three (18.8\%) had urinary incontinence, three (18.8\%) had fecal retention and two (12.5\%) had urinary retention. Among the eight skull base resections, one (12.5\%) developed strabismus and two (25\%) persistent swallowing disorders.

\section{Nonsurgical treatment}

Fourteen patients $(33.3 \%)$ did not undergo surgical treatment in our hospital. Twelve (28.6\%) patients had locally advanced tumors that were considered unresectable and the last two (4.7\%) received only palliative support because of their poor clinical conditions. Of these, six patients had undergone surgery in another hospital, with incomplete resection. The tumors were considered unresectable based on imaging studies, in which the tumor was seen to involve the S1 sacral level in eight cases, had extensive skull base infiltration in three cases, and involved levels from C3 to T2 in one case. Ten patients (23.8\%) were administered palliative radiotherapy and two (4.8\%) were administered palliative chemotherapy.

\section{Radiotherapy}

Radiotherapy was used for 19 patients of this sample: four patients with negative margins, five patients with positive margins and ten patients with inoperable disease.

The type of radiotherapy currently used in our institution is intensity-modulated radiation therapy (IMRT).

\section{Recurrence}

Among the 14 patients who underwent resection with negative margins, six (42.8\%) had local recurrence. Five were sacral tumors and one had received adjuvant radiotherapy. The remaining patient had a skull base tumor and did not receive adjuvant radiotherapy.

In the group with positive margins, four patients $(28.5 \%)$ had stable disease during the follow-up, seven (50\%) had only local progression and three developed metastases (21.4\%): one with pulmonary disease alone and two with both local progression and distant disease (pulmonary and bone; pulmonary and hepatic). In the group that was considered inoperable, there were three patients $(21.4 \%)$ that developed systemic metastasis (one skin and one lung).

From analysis on the group with negative margins, the fiveyear progression-free survival rate was $74 \%$. The primary tumor site also did not influence the risk of recurrence $(\mathrm{P}=0.11)$. Regarding adjuvant radiotherapy, no conclusion could be reached because only four patients (25\%) with negative margins received adjuvant radiotherapy.

\section{Overall survival}

From the analysis on the whole sample, surgical treatment (Figure 1, P $<0.001$ ) and surgical resection with negative margins (Figure $2, \mathrm{P}=0.021$ ) were the only variables that influenced the risk of death in univariate analysis (Figures 1 and 2). Other variables like sex $(P=0.92)$, previous tumor manipulation $(P=0.16)$, tumor location $(\mathrm{P}=0.87)$ and adjuvant radiotherapy $(\mathrm{P}=0.845)$ did not influence overall survival.

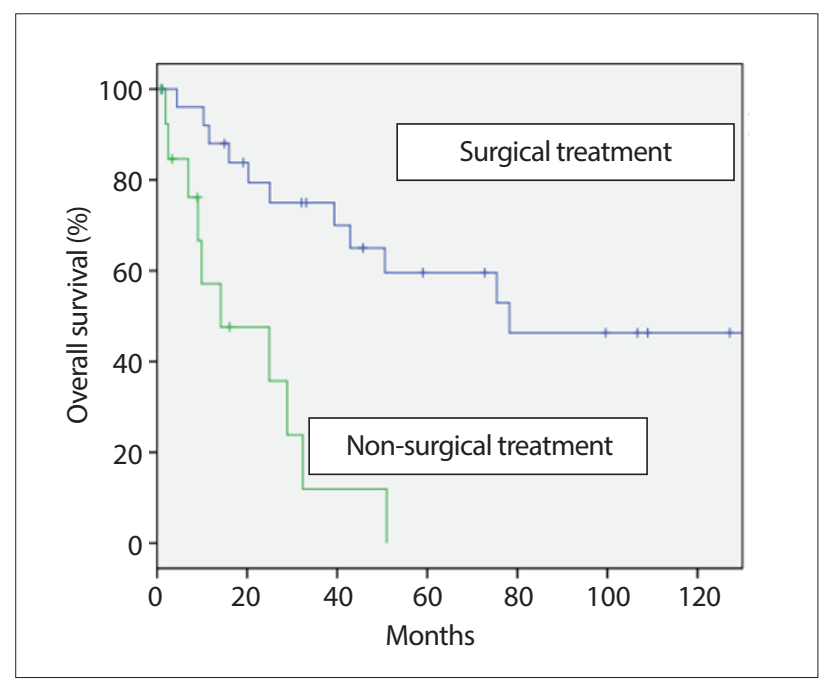

Figure 1. Kaplan-Meier curves for overall survival from surgical and nonsurgical treatment $(P<0.001)$.

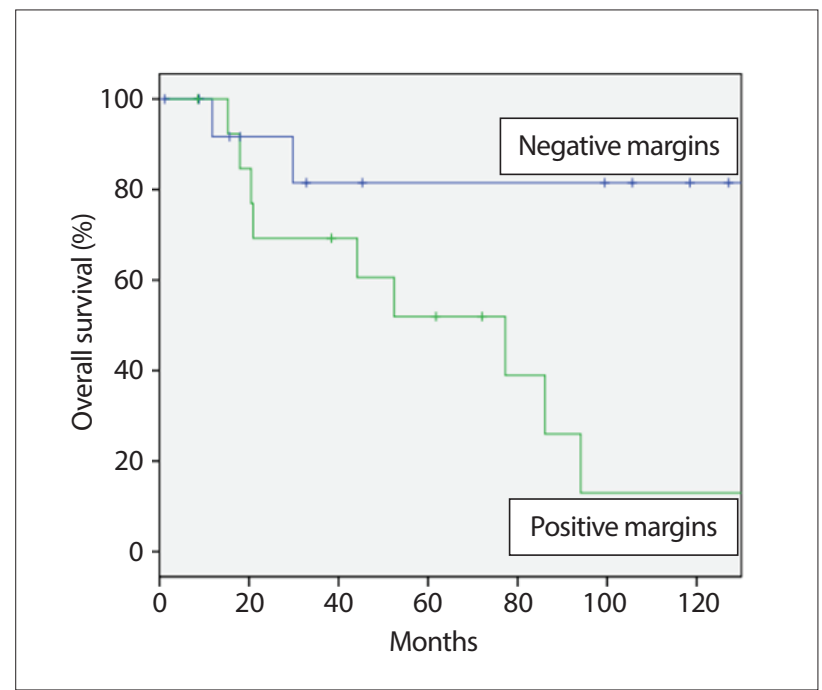

Figure 2. Kaplan-Meier curves for overall survival from resection with negative margins and resection with positive margins $(P=0.021)$. 
Regarding the 14 patients who received nonsurgical/palliative treatment, one patient submitted to palliative support was lost from the follow-up. The median survival in this group was 9.7 months (range: 1.0-50.3). Of these, ten had undergone radiotherapy, two received chemotherapy alone and two received only best supportive care.

The median lengths of survival of the 10 patients who underwent radiotherapy, two patients who underwent chemotherapy and patient with palliative support were respectively 9.76, 13.0 and 7.4 months. There were no difference in survival between radiotherapy and chemotherapy in the nonsurgical group $(P=0.316)$.

Age did not affect survival. When we divided patients into two groups based on the median age, there was no statistical difference in overall survival between patients over and under the age of 47 years.

The five-year overall survival for all patients was $45.4 \%$. Among the patients who underwent a surgical procedure, the five-year overall survival was $64.3 \%$ (82.2\% for resections with negative margins and $51.9 \%$ for resections with positive margins). In the inoperable group, survival at 24 months was $37.7 \%$ and at five years, all patients had died due to the disease.

\section{DISCUSSION}

Chordoma is a rare malignant bone tumor originating in the axial skeleton, although it is the most common sacral primary neoplasm. ${ }^{8,9}$ The sacrum accounts for $50 \%$ of the primary sites for chordoma, followed by the skull base (35\%) and mobile spine (15\%). ${ }^{1-3}$ Almost the same distribution was also seen in our study (59.5\% located in the sacrum, $26.2 \%$ in skull base and $14.3 \%$ in the mobile spine).

Because of the rarity of this disease, most of the previous clinical reports are based on retrospective series, with a long period of follow-up and with various types of treatment. ${ }^{2}$ When patients present with symptoms, they usually have radicular pain and sensory disorders relating to nerve root compression. The nonspecific symptoms often account for the diagnosis delay, with a median time period of 12 to 24 months. ${ }^{1,10}$ Our series corroborated these findings, with a median time period of 12 months before the diagnosis was confirmed.

Surgery is the mainstay of treatment. Wide en bloc resection with adequate bone and soft tissue margins is the primary surgical goal $2^{2,6,711}$ and is the main prognostic factor for local recurrence and an important predictor of mortality. ${ }^{12-15}$ However, sometimes, wide margins are very difficult to attain because these tumors are located at sites that are difficult to access, with high rates of complications and sequelae.

Kaiser et al. ${ }^{11}$ reported that local failure correlated with surgical tumor margin violation. They showed a local recurrence rate of $28 \%$ for patients who had completed en bloc resection and $64 \%$ if the tumor capsule was violated. York et al. ${ }^{7}$ reported a statistically significant difference in local failure between patients who underwent radical resection (2.3 years) and those who had incomplete excision (eight months). Bergh et al. ${ }^{2}$ demonstrated that local control was highly improved with more aggressive surgery. Only $17 \%$ of patients with wide margin resection developed local recurrences. On the other hand, local recurrences occurred in $81 \%$ of the patients who underwent intralesional or marginal surgery. The latter authors also showed that local recurrence was significantly associated with an increased risk of metastasis and tumor-related death.

In our report, surgical resection was the only variable that had a positive impact on overall survival. Patients who underwent resections with negative margins showed a better prognosis then those with positive margins. No patient with negative margins developed distant recurrence, even after local recurrence. Surgical resection had a critical value regardless of the primary site of the tumor.

The role of radiotherapy as primary or adjuvant treatment for chordoma has been investigated. ${ }^{16-20}$ Some authors, such as York et al., ${ }^{7}$ have reported prolonged progression-free survival with radiotherapy for patients with subtotal resection, whereas others have reported that this had little effect. Because of the small sample that underwent adjuvant radiotherapy in the present study, our report is too limited to formulate any conclusion. In our institution, IMRT is used. Some authors have described potential benefits from carbon ion radiotherapy, but we do not have this technology in our institution. ${ }^{21,22}$

The quality of primary treatment is reflected in the surgical margins attained in the definitive surgery and seems to be critical for the final outcome. Among the patients who underwent resection with negative margins, $62.5 \%$ of them did not develop local recurrences. This factor was correlated with better five-year overall survival (84.4\%). Among the 13 patients who had undergone incomplete resections in other institutions, seven (53.8\%) had resections with negative margins in our hospital, with an obvious impact on survival for these patients. This finding supports the idea that primary surgery should be performed within a specialized multidisciplinary cancer center.

This study has some limitations because it was conducted retrospectively, but it will certainly help other researchers and surgeons to better understand this rare disease. It also raises some questions about the definitive role of adjuvant radiotherapy after incomplete resection, and inspires investigation about the role of other adjuvant treatments such as tyrosine kinase inhibitors. These issues might need to be addressed by further studies.

\section{CONCLUSION}

The primary goal in treating chordoma is still adequate surgical resection, and every effort needs to be made towards enabling 
complete removal of sacral, spinal and skull base chordomas. Complete resection is related to local control and definitively has a positive impact on survival.

\section{REFERENCES}

1. Baratti D, Gronchi A, Pennacchioli E, et al. Chordoma: natural history and results in 28 patients treated at a single institution. Ann Surg Oncol. 2003;10(3):291-6.

2. Bergh P, Kindblom LG, Gunterberg B, et al. Prognostic factors in chordoma of the sacrum and mobile spine: a study of 39 patients. Cancer. 2000;88(9):2122-34.

3. Eriksson B, Gunterberg B, Kindblom LG. Chordoma. A clinicopathologic and prognostic study of a Swedish national series. Acta Orthop Scand. 1981;52(1):49-58.

4. Fourney DR, Gokaslan ZL. Current management of sacral chordoma. Neurosurg Focus. 2003;15(2):E9.

5. Lopes A, Rossi BM, Silveira CR, Alves AC. Chordoma: retrospective analysis of 24 cases. Sao Paulo Med J. 1996;1 14(6):1312-6.

6. Azzarelli A, Quagliuolo V, Cerasoli S, et al. Chordoma: natural history and treatment results in 33 cases. J Surg Oncol. 1988;37(3):185-91.

7. York JE, Kaczaraj A, Abi-Said D, et al. Sacral chordoma: 40-year experience at a major cancer center. Neurosurgery. 1999;44(1):74-9; discussion 79-80.

8. Crapanzano JP, Ali SZ, Ginsberg MS, Zakowski MF. Chordoma: a cytologic study with histologic and radiologic correlation. Cancer. 2001;93(1):40-51.

9. Xu WP, Song XW, Yue SY, Cai YB, Wu J. Primary sacral tumors and their surgical treatment. A report of 87 cases. Chin Med J (Engl). 1990;103(11):879-84.

10. Chandawarkar RY. Sacrococcygeal chordoma: review of 50 consecutive patients. World J Surg. 1996;20(6):717-9.

11. Kaiser TE, Pritchard DJ, Unni KK. Clinicopathologic study of sacrococcygeal chordoma. Cancer. 1984;53(11):2574-8.

12. Fuchs B, Dickey ID, Yaszemski MJ, Inwards CY, Sim FH. Operative management of sacral chordoma. I Bone Joint Surg Am. 2005;87(10):2211-6.

13. Boriani S, Bandiera S, Biagini R, et al. Chordoma of the mobile spine: fifty years of experience. Spine (Phila PA 1976). 2006;31(4):493-503.

14. Osaka $\mathrm{S}$, Kodoh $\mathrm{O}$, Sugita $\mathrm{H}$, et al. Clinical significance of a wide excision policy for sacrococcygeal chordoma. J Cancer Res Clin Oncol. 2006;132(4):213-8.

15. Tzortzidis F, Elahi F, Wright D, Natarajan SK, Sekhar LN. Patient outcome at long-term follow-up after aggressive microsurgical resection of cranial base chordomas. Neurosurgery. 2006;59(2):230-7; discussion 230-7.

16. Ferraresi V, Nuzzo C, Zoccali C, et al. Chordoma: clinical characteristics, management and prognosis of a case series of 25 patients. BMC Cancer. 2010;10:22.
17. Magrini SM, Papi MG, Marletta F, et al. Chordoma-natural history, treatment and prognosis. The Florence Radiotherapy Department experience (1956-1990) and a critical review of the literature. Acta Oncol. 1992;31(8):847-51.

18. Mindell ER. Chordoma. J Bone Joint Surg Am. 1981;63(3):501-5.

19. Sciubba DM, Cheng JJ, Petteys RJ, et al. Chordoma of the sacrum and vertebral bodies. J Am Acad Orthop Surg. 2009;17(11):708-17.

20. Bjornsson J, Wold LE, Ebersold MJ, Laws ER. Chordoma of the mobile spine. A clinicopathologic analysis of 40 patients. Cancer. 1993;71(3):735-40.

21. Imai R, Kamada T, Sugahara S, Tsuji H, Tsujii H. Carbon ion radiotherapy for sacral chordoma. Br J Radiol. 2011;84 Spec No 1:S48-54.

22. Combs SE, Kalbe A, Nikoghosyan A, et al. Carbon ion radiotherapy performed as re-irradiation using active beam delivery in patients with tumors of the brain, skull base and sacral region. Radiother Oncol. 2011;98(1):63-7.

Sources of funding: None

Conflict of interest: None

Date of first submission: November 16, 2012

Last received: August 19, 2013

Accepted: October 22, 2013

\section{Address for correspondence:}

Wesley Pereira Andrade

Departamento de Mastologia

Rua Prof. Antonio Prudente, 211

Liberdade — São Paulo (SP) — Brasil

CEP 01509-900

E-mail:wesley.andrade@hotmail.com 